\title{
Testing General and Special Färe-Primont Indices: A Proposal for Public and Private Sector Synthetic Indices of European Regional Expenditures and Tourism*
}

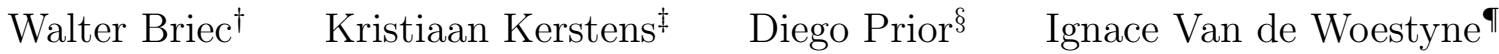

August 2017

Revised: January 2018

This version: May 2018

\begin{abstract}
This contribution develops a general and a special case of the Färe-Primont total factor productivity index that has the critical property of transitivity for application in the tourism sector. In particular, its empirical application focuses on the respective contributions of public and private expenditures to the economic activity of tourism services at a regional level in Europe. Since the focus of measurement is oriented towards tourism activity, this synthetic index can be interpreted as a tourism effectiveness index. Depending on how the variables are included in the underlying technology specification, the same tourism index can be oriented towards the assessment of either the private or the public sectors effectiveness. Consequently, the existing interdependencies between both sectors can be estimated. The empirical application contains a sample of European regions in the three years 2003, 2007 and 2011.
\end{abstract}

JEL: L83, D24, C43.

Keywords: Data Envelopment Analysis, Total factor productivity growth, Färe-Primont index, Synthetic index, tourism industry.

${ }^{*}$ We thank three referees of this journal for their most constructive comments. The usual disclaimer applies. Diego Prior acknowledges the financial support from the Spanish Ministry of Economy, Industry and Competitiveness, ref. ECO2017-88241-R.

${ }^{\dagger}$ GEREM, Université de Perpignan Via Domitia, 52 Avenue Villeneuve, F-66000 Perpignan, France.

${ }^{\ddagger}$ CNRS-LEM (UMR 9221), IESEG School of Management, 3 rue de la Digue, F-59000 Lille, France. k.kerstens@ieseg.fr, Corresponding author.

${ }^{\S}$ Department of Business, Universitat Autònoma de Barcelona, 08193 Bellaterra (Barcelona), Spain and IESEG School of Management.

`KU Leuven, Research unit MEES, Warmoesberg 26, B-1000 Brussel, Belgium. 


\section{Introduction}

The notion of Total Factor Productivity (TFP) growth is normally defined as an index number representing technology shifts from growth in the outputs which remain unexplained by growth in the inputs (see, e.g., the Hulten (2001) survey). In the last decades, people have realised that ignoring inefficiency may well lead to a bias of TFP measures. The seminal article decomposing TFP into technical change and technical efficiency change components is Nishimizu and Page (1982).

Caves, Christensen, and Diewert (1982) provide a seminal contribution for analysing input, output and productivity indices in discrete time using distance functions as general representations of technology. They define both output-based and input-based primal Malmquist productivity indices that require a precise knowledge of technology and its physical inputs and outputs. Assuming these productivity indices could not be empirically applied, these indices were approximated by the wellknown Törnqvist productivity indices that need no exact knowledge of technology. Färe, Grosskopf, Lindgren, and Roos (1995) estimate the distance functions in the Malmquist productivity index by exploiting their inverse relation with the radial efficiency measures computed relative to general nonparametric technologies, thereby also integrating the two-part Nishimizu and Page (1982) decomposition. The distance functions of this Malmquist productivity index can also be parametrically estimated (e.g., Atkinson, Cornwell, and Honerkamp (2003)). The Malmquist productivity indices are nowadays widely used in the non-parametric and parametric frontier literature.

Developing some hints in the literature, Bjurek (1996) defined an alternative primal Malmquist TFP or Hicks-Moorsteen index. It is a ratio of a Malmquist output quantity index over a Malmquist input quantity index, which has a strong general appeal as a TFP index. Intuitively stated, this means that it can always be interpreted similar to a change in average productivity. One important advantage of the latter index in our context of application is that it is neither input- nor outputoriented (like the Malmquist index), which avoids the risk of specification error. This TFP index has been less widely applied than the extremely popular Malmquist index: some examples include Epure, Kerstens, and Prior (2011), Nemoto and Goto (2005), and Zaim, Färe, and Grosskopf (2001), among others. The Malmquist and Hicks-Moorsteen productivity indices are known to be identical under strong conditions only. Therefore, both indices are in general expected to differ in empirical work. An advantage of the Hicks-Moorsteen productivity index is that it is always determinate under weak conditions (see Briec and Kerstens (2011)), while this is not the case for the Malmquist index (e.g., see Briec and Kerstens (2009) for details).

Though both these primal productivity indices have become relatively popular in empirical work in the last decade or so, O'Donnell (2012) convincingly shows that the Malmquist productivity index is not an TFP index that is multiplicatively complete while Hicks-Moorsteen TFP index experiences

no such problem. Peyrache (2014, p. 435) explicitly argues that the Malmquist productivity index is in fact a "technology index, i.e. a measure of local technical progress (or regress)". The Malmquist productivity index thus measures the local change in the production frontier at a specific point. 
Kerstens and Van de Woestyne (2014) empirically show that the Malmquist productivity index does not offer a good approximation to the Hicks-Moorsteen TFP index in terms of the resulting distributions. For individual observations, one may even encounter conflicting evidence regarding the basic direction of TFP growth or decline.

Furthermore, as underscored by the recent work of O'Donnell (2014) this Hicks-Moorsteen TFP index can be made transitive by a proper choice of basis: choosing a fixed basis allows for multi-lateral and multi-temporal (instead of only binary) comparisons. In fact, the specific way to make this TFP index transitive goes back to proposals launched by Färe and Primont (1995, pp. 36-38), predating the Bjurek (1996) proposal. Therefore, O'Donnell (2014) baptises the fixed base version of this Hicks-Moorsteen index a Färe-Primont (F-P) productivity index. Given its direct relation to the Hicks-Moorsteen productivity index, the F-P index normally inherits its properties (e.g., determinateness). Empirical applications of this F-P index are still relatively rare: examples include Arjomandi, Harvie, and Valadkhani (2012), Islam, Xayavong, and Kingwell (2014), Nguyen and Simioni (2015), and Rahman and Salim (2013), among others. ${ }^{1}$ In addition, O'Donnell (2011a) develops a special case of the F-P productivity index by imposing additional assumptions on technology (this version is embodied in the software program DPIN). In fact, a substantial part of the few empirical applications of this F-P index do employ this special case of the F-P productivity index. Therefore, an important first methodological objective of this contribution is then to check to which extent the general and special versions of the F-P productivity index yield similar or dissimilar empirical results.

Tourism has become an important activity in the portfolio of economic activities in many countries. Existing efficiency studies have either focused on privately owned facilities (e.g., hotels, restaurants, travel agencies, etc.) or on public sector tourism infrastructures (e.g., museums, national parks, theaters, etc.). In the literature, there is a lack of articles attempting to judge the efficiency and productivity aspects of tourism policies at the macro level. Therefore, a second methodological objective of the present contribution is to assess the contribution of regions and their public services to all tourism activities within their territorial boundaries which allows tracking the evolution of performance over time. We attempt to gauge the contribution of key public infrastructure inputs to the tourism services offered by the private sector using a Färe-Primont productivity index. This basic TFP index is here considered as a synthetic index capable of gauging the effectiveness of regional infrastructure outlays in promoting tourism activities. Our study is exploratory in nature and looks at the problems of defining such a synthetic regional policy effectiveness index, its validation with data sources corresponding to European regions, and how observed variations in performance can eventually be traced back to both environmental conditions and competitiveness parameters. The latter explanatory statistical analysis is, of course, most important in terms of formulating public policy conclusions.

\footnotetext{
${ }^{1}$ A Google Scholar search on 16 August 2017 obtained 125 results for the expression "Färe-Primont productivity". By contrast, the expressions "Malmquist productivity" and "Hicks-Moorsteen productivity" yield 23600 and 475 results respectively.
} 
The structure of this contribution is as follows. Section 2 deals with the conceptual problems when evaluating regional policy efficiency and effectiveness indices. The next section introduces some definitions on technologies and their functional representations under the form of distance functions. The latter functions are the building blocks for defining productivity indices in general and also for the synthetic Färe-Primont index used in our empirical application in particular. A detailed description of the sample and the specification of the technology retained are provided in Section 4. Empirical results are analysed in detail in Section 5. A concluding section summarises our main findings and adds some critical notes for future research.

\section{Regional Performance Measurement: Context, Concepts and Informational Requirements}

\subsection{Context: Literature Review}

Assessing the performance of public service organizations at the regional level can be done using a wide variety of performance indicators, including financial measures (debt ratios, per capita expenditures or revenues, etc.), efficiency measures and indices of effectiveness (i.e., of the degree to which certain policy objectives have been realized). Nowadays, performance gauging focuses most frequently on technical and cost efficiency. This issue of the efficient provision of public services has been rather widely studied. Not only global assessments of the municipal supply of public services have been developed (e.g., Hayes and Chang (1990)), but also detailed studies focusing on particular services (e.g., Bouckaert (1993) on civil registry, or Deller and Nelson (1991) on local roads). To our knowledge, studies on public service provision at the regional level are rather scarce (see Nemoto and Goto (2005) or Seifert and Nieswand (2014) for some examples). The present contribution is situated in the latter tradition and focuses on tourism-related expenditures at the regional level.

While tourism has become a major part of some countries economic activities, the existing published efficiency studies in this field have mainly focused on privately owned facilities. Popular topics of study have been hotels (e.g., Barros, Peypoch, and Solonandrasana (2009)), restaurants (for instance, Giménez-García, Martínez-Parra, and Buffa (2007)), ski resorts (e.g., Goncalves (2013)), and travel agencies (e.g., Sellers-Rubio and Nicolau-Gonzálbez (2009)), among others. Alternatively, some efficiency studies have attempted to evaluate the performance of public sector tourism infrastructures like museums (e.g., Mairesse and Vanden Eeckaut (2002)), national parks (for instance, Bosetti and Locatelli (2006)) or theaters (e.g., Last and Wetzel (2010)).

The notion of productivity is complex and multi-faceted to develop and apply in the tourism sector with its wide range of private and public sector activities (see, e.g., Ritchie and Crouch (2003) for an overview). There is a rather substantial literature using traditional average prac- 
tice specifications of technology and limiting itself to partial productivity indicators (for example, McMahon (1994)). Furthermore, a wide range of methodologies has been used to gauge productivity changes. One example is the work by Blake, Sinclair, and Soria (2006) that uses computable general equilibrium models to evaluate productivity change. A lot of recent studies have opted for studying productivity change using primal Malmquist productivity indices based on best practice frontier technology specifications. Limiting ourselves to the hotel industry, examples of such Malmquist productivity studies include Assaf and Agbola (2011), Barros, Peypoch, and Solonandrasana (2009), and Yu and Chen (2016), among others.

Within a more theoretical approach, there are also proposals to analyse efficiency and productivity in the tourism sector at an aggregate level (see Peypoch and Solonandrasana (2008)). Furthermore, one can mention some other isolated attempts to judge certain aspects of tourism policies at the macro level. For instance, Botti, Goncalves, and Ratsimbanierana (2012) develop a mean-variance portfolio approach to help destination management organizations minimize instability and maximizing return of inbound tourism, while Wober and Fesenmaier (2004) assess the efficiency of advertising budgets of state tourism offices in the United States. Cracolici, Nijkamp, and Rietveld (2008) come closest to what we want to achieve when evaluating 103 Italian regions for the single year 2001: the single output bed-nights relative to population is related to proxies for cultural and historical capital, human capital, and labour inputs. The main purpose of the present study is to assess the contribution of regions and their public services to all tourism activities within their territorial boundaries which allows tracking the evolution of performance over time (rather than an evaluation at just a single point in time). In particular, we focus on the contribution of important public infrastructure inputs to the tourism services offered by the private sector using a TFP index.

Inspired by existing applications in the efficiency literature (e.g., Epure, Kerstens, and Prior (2011), Ramos and Silber (2005), or Zaim, Färe, and Grosskopf (2001)), we transform a basic TFP index based upon distance functions into a synthetic index capable of gauging the effectiveness of regional infrastructure outlays in promoting tourism activities. ${ }^{2}$ The use of distance functions evaluated with respect to technologies with minimal axiomatic structure is just one way to define so-called synthetic or composite indices aimed at evaluating the success or effectiveness of private and public policies promoting tourism at the regional level. An alternative methodology would be the use of principal components (see Somarriba and Pena (2009) for a discussion of various methodologies to define synthetic or composite indices). The resulting synthetic index has wellestablished axiomatic properties. Distance functions, as complete characterisations of multiple input-output technologies, are not only useful for evaluating performance in production, but have also hitherto rather neglected possibilities as aggregator functions in gauging policy success or effectiveness. Given the difficulties to precisely formulate the underlying production technology

\footnotetext{
${ }^{2}$ This is not the only possible definition of effectiveness in the tourism industry. For instance, Keh and Chu (2006) define effectiveness in the tourism industry from an alternative marketing perspective (ignoring the effect of public intervention).
} 
(especially for the public secor), nonparametric, deterministic frontier technologies based upon activity analysis are employed because of their minimal assumptions. These technologies are well founded in axiomatic production theory and are furthermore very flexible (see, e.g., Hackman (2008)). Furthermore, we develop a double and complementary perspective by defining both a public and private TFP index to evaluate the effectiveness of both the private and public sector using a common aggregate technology specification. We are unaware of any performance assessment in this area taking such an overall and complementary perspective in the existing literature. This synthetic regional policy effectiveness index is similar in spirit to the synthetic or composite indices advocated by, e.g., Ramos and Silber (2005) (see also Somarriba and Pena (2009) on synthetic indices).

\subsection{Concepts and Informational Requirements}

Translating the production process at the regional level in terms of the standard notion of a production technology transforming inputs into outputs is no trivial problem. In principle, measurement of efficiency notions is straightforward if reliable data are available on both quantities and prices of all inputs and outputs of the production process. While this poses in principle little problem at the micro level, a variety of specification issues may arise at the meso (e.g., region or sector) and macro level (e.g., country).

Furthermore, when some necessary information is unavailable, then we are restricted in the type of efficiency that can be measured. For instance, technical efficiency solely requires data on inputs and outputs, while allocative efficiency can only be estimated if also price information is available. Consequently, the type of information available conditions to some extent the flexibility of performance measurement (e.g., Hackman (2008)).

For the purpose of evaluating the effectiveness of regions in facilitating and promoting tourism within their territorial boundaries, we basically see regions as public service providers that offer, among others, various public infrastructures that are complementary to private sector production processes within their territory. When evaluating the economic results of this combination of public and private production activities, one would ideally need a complete specification of this whole production process.

However, this is a task that likely surpasses both current modelling options and data availabilities. Instead, we focus on the inputs provided by the regions and check how these ultimately translate into commercial and tourism activities of the private sector. In brief, the indirect approach adopted in our study evaluates the transformation from public expenditures into private economic activities, with a particular focus on tourism.

Our proposed synthetic index of effectiveness improves upon the existing empirical literature in tourism in four respects. First, in contrast to most multilateral and apparently partial productivity 
indicators (e.g., McMahon (1994)), the use of distance functions based upon explicit best practice production technologies ensures that endogenously determined weights are employed. The distance function then aggregates the multiple inputs and multiple outputs in the technology with weights determined by the data in the sample. Second, the success of a region in contributing to the expansion of tourism activities is evaluated by measuring the distance to a best practice technology that serves as a common benchmark. This best practice technology is constructed from observed inputs and outputs and is different from traditional average practice specifications of technology. Three, the choice of the Färe-Primont TFP index that normally satisfies the properties of determinateness and transitivity improves upon any other productivity index that may be around in the literature. Fourth, the proposal to focus on a complementary perspective by defining both a public and private TFP index to evaluate the effectiveness of both the private and public sector using a common aggregate frontier technology is new to the literature. To the best of our knowledge, these features of our synthetic index (based upon economic index theory) are new and unique in the analysis of tourism.

\section{Technology, Distance Functions and Färe-Primont Productivity Indices}

\subsection{Färe-Primont Productivity Index: General Framework}

This section introduces the assumptions on the production possibility set and the methods to measure efficiency leading to the definition of the F-P index. Introducing some notation, one observes for $K$ observations (i.e., the total number of observations over all time periods) $M$ inputs $\left(x \in \mathbb{R}_{+}^{M}\right)$ producing $N$ outputs $\left(y \in \mathbb{R}_{+}^{N}\right)$. Production technology is defined by the set of feasible input and output vectors: $S=\{(x, y) \mid x$ can produce $y\}$. If necessary, sub-technologies can be obtained by selecting all observations recorded in the same time frame. It is also useful to consider the output and input sets associated with technology. For a given input vector $x$, the output set denotes all output vectors $y$ that can be produced from the given input vector $x$ : $(P(x)=\{y \mid(x, y) \in S\})$. Also, for a given output vector $y$, the input set denotes all input vectors $x$ that are capable of producing this output vector: $(L(y)=\{x \mid(x, y) \in S\})$. Obviously, the notions of output and input sets are also applicable to time frame limited sub-technologies.

The next theoretical building block is the output distance function:

$$
D_{o}(x, y)=\min \{\theta \mid(y / \theta) \in P(x)\} .
$$

Treating inputs as given, this distance function expands the output vector as much as possible proportionally while staying within $P(x)$. More precisely, the output distance function completely characterizes technology: $D_{o}(x, y)=1 \Leftrightarrow y \in \operatorname{Isoq} P(x)=\{y \mid y \in P(x), \theta y \notin P(x)$ for $\theta>1\}$ and 
$D_{o}(x, y) \leq 1 \Leftrightarrow y \in P(x)$. The output distance function inflates the output vector until it belongs to the isoquant of the output set (Hackman (2008)). Completely analogous, an input distance function is defined as:

$$
D_{i}(x, y)=\max \{\theta \mid(x / \theta) \in L(y)\}
$$

Treating outputs as given, it proportionally contracts the input vector by as much as possible while staying in $L(y)$. Again, the input distance function characterizes technology: $D_{i}(x, y)=1 \Leftrightarrow x \in$ Isoq $L(y)$ and $D_{i}(x, y) \geq 1 \Leftrightarrow x \in L(y)$. In the analysis following hereafter, these distance functions play the triple role of representations of technology, efficiency or distance measures, and aggregator functions.

Keeping in mind the static nature of our analysis, the F-P TFP index (O'Donnell (2014)) measuring the productivity of observation $\left(x^{l}, y^{l}\right)$ with respect to $\left(x^{k}, y^{k}\right)$, and using a fixed reference input-output combination determined by $\left(x^{o}, y^{o}\right)$, is defined as the ratio of a F-P output quantity index and a F-P input quantity index:

$$
\operatorname{FP}\left(x^{o}, y^{o}, x^{k}, y^{k}, x^{l}, y^{l}\right)=\frac{\operatorname{FPO}\left(x^{o}, y^{k}, y^{l}\right)}{\operatorname{FPI}\left(x^{k}, x^{l}, y^{o}\right)}
$$

whereby the F-P output quantity index is defined as $\operatorname{FPO}\left(x^{o}, y^{k}, y^{l}\right)=\frac{D_{o}\left(x^{o}, y^{l}\right)}{D_{o}\left(x^{o}, y^{k}\right)}$ and the F-P input quantity index is defined as $\operatorname{FPI}\left(x^{k}, x^{l}, y^{o}\right)=\frac{D_{i}\left(x^{l}, y^{o}\right)}{D_{i}\left(x^{k}, y^{o}\right)}$.

Three remarks are at place. First, note that indexes $k, l \in\{1, \ldots, K\}$ refer to two observations available in the overall technology (i.e., all observations over all time periods). Several possibilities can be realized depending on the choice of these indexes (e.g, two different regions observed at the same time period, the same region observed at different time periods, or two different regions observed at different time periods).

Second, in the single input-output case, one can easily demonstrate that $\operatorname{FPO}\left(x^{o}, y^{k}, y^{l}\right)=$ $\frac{D_{o}\left(x^{o}, y^{l}\right)}{D_{o}\left(x^{o}, y^{k}\right)}=\frac{y^{l}}{y^{k}}$, regardless the choice of $x^{o}$. Similarly, $\operatorname{FPI}\left(x^{k}, x^{l}, y^{o}\right)=\frac{D_{i}\left(x^{l}, y^{o}\right)}{D_{i}\left(x^{k}, y^{o}\right)}=\frac{x^{l}}{x^{k}}$, regardless the choice of $y^{o}$. Hence, in this special case, the F-P output and input indexes do not depend on the choice of the fixed reference input-output combination $\left(x^{o}, y^{o}\right)$. Moreover, these F-P indexes are now directly linked to outputs and inputs: the F-P output quantity index larger (smaller) than unity indicates that more (less) output is produced by observation $l$ than by observation $k$; the F-P input quantity index smaller (larger) than unity corresponds with less (more) input being used by observation $l$ compared to observation $k$. Obviously, this independence of the choice of $\left(x^{o}, y^{o}\right)$ and the direct link with inputs and outputs no longer hold true in the a multidimensional input-output scenario. Concerning the former, O'Donnell (2014) suggests using average inputs and outputs taken over all observations for this fixed reference point. Epure, Kerstens, and Prior (2011) suggest taking any benchmark firm within the industry of strategic relevance as a reference input-output combination. In Section 5, we use yet another choice due to practical reasons related to zero inputs present in the data. 
Third, the distance functions occurring in the F-P indexes are all computed with respect to the same technology. This requirement turns the F-P productivity index into a transitive index contrary to other productivity indexes such as the Malmquist index. ${ }^{3}$ Different choices for this same technology can be used (e.g., the technology observed at a certain time period, or the overall technology obtained by including all observations over time). Following the suggestion of O'Donnell (2011b), we have opted for the latter choice in this contribution. ${ }^{4}$

Interpretations for the F-P TFP index and its components can be provided as follows. Given some fixed reference input $x^{o}$, the F-P output quantity index compares the output efficiency of $\left(x^{o}, y^{l}\right)$ with that of $\left(x^{o}, y^{k}\right)$. The F-P output quantity index larger (smaller) than unity implies that observation $l$ is more (less) efficient in its outputs than observation $k$. Given some fixed reference output $y^{o}$, the F-P input quantity index compares the input efficiencies of $\left(x^{k}, y^{o}\right)$ and $\left(x^{l}, y^{o}\right)$. If this F-P input quantity index is smaller (larger) than unity, then observation $l$ is more (less) efficient in its inputs compared to observation $k$. Consequently, the F-P index (3) being the ratio of the F-P output and input quantity indexes measures the productivity of observation $l$ compared to observation $k$ assuming the fixed reference input-output combination $\left(x^{o}, y^{o}\right)$.

Empirical applications of the the F-P index are still relatively rare. We briefly mention some examples from a variety of sectors. In agriculture, studies cover Australia (Islam, Xayavong, and Kingwell (2014)) and Bangladesh (Rahman and Salim (2013)), among others. One additional study focuses on US fisheries (see Färe, Grosskopf, and Walden (2015). Two studies analyse the banking sector in Iran (Arjomandi, Harvie, and Valadkhani (2012)) and Vietnam (Nguyen and Simioni (2015)). Widodo, Salim, and Bloch (2014) study a variety of manufacturing sectors in Indonesia, while Carrington, O'Donnell, and Rao (2018) assess Australian universities and Chancellor and Abbott (2015) evaluate the Australian construction industry. Finally, Molinos-Senante, Maziotis, and Sala-Garrido (2017) investigate the English and Welsh water industry.

\subsection{Färe-Primont Productivity Index: A Special Case}

From Section 3.1, it is clear that the F-P TFP index depends on a particular choice of the fixed reference input $x^{o}$ and output $y^{o}$ which influences the corresponding F-P indexes in a multidimensional setting. This effect can be reduced by imposing additional assumptions on technology, the latter being the case in the software program DPIN (see O'Donnell (2011a)). For a better understanding, we elaborate in this section on these additional assumptions based on O'Donnell (2011a,b) and O'Donnell (2014).

\footnotetext{
${ }^{3}$ The traditionally defined Malmquist index does not satisfy transitivity. However, an alternative such as the global Malmquist productivity index introduced by Pastor and Lovell (2005) is transitive since the underlying distance functions are measured with respect to a single overall technology, i.e., the convex hull of the union of all technologies over all time periods.

${ }^{4}$ As noted in the context of the global Malmquist productivity index introduced by Pastor and Lovell (2005), this measurement with respect to a single overall technology creates a type of base period dependency in that the index must be recomputed whenever a new time period is added.
} 
It is assumed that technology is

(i) extended output homothetic, i.e., $D_{o}(x, y)=\frac{g(x)}{g\left(\mu_{x}\right)} D_{o}\left(\mu_{x}, y\right)$ for some $g: \mathbb{R}_{+}^{M} \rightarrow \mathbb{R}_{+}$and an arbitrary $\mu_{x} \in \mathbb{R}_{+}^{M}$

(ii) homogeneous of degree $r \in \mathbb{R}_{+}$, i.e., $D_{o}(\lambda x, y)=\lambda^{-r} D_{o}(x, y)$.

(iii) extended Hicks output neutral. ${ }^{5}$

As a consequence, the F-P index (3) can be rewritten as

$$
\hat{\mathrm{FP}}\left(x^{o}, y^{o}, x^{k}, y^{k}, x^{l}, y^{l}\right)=\frac{Q\left(y^{l}\right) X\left(x^{k}\right)}{Q\left(y^{k}\right) X\left(x^{l}\right)},
$$

for some aggregator functions $Q: \mathbb{R}_{+}^{M} \rightarrow \mathbb{R}_{+}$and $X: \mathbb{R}_{+}^{N} \rightarrow \mathbb{R}_{+}$. The software program DPIN uses the specific choices $Q(y)=\sum_{m=1}^{M} y_{m} p_{m}^{o}$ and $X(x)=\sum_{n=1}^{N} x_{n} w_{n}^{o}$, with $p^{o}$ the shadow price vector computed from $D_{o}\left(x^{o}, y^{o}\right)$ and $w^{o}$ the shadow price vector computed from $D_{i}\left(x^{o}, y^{o}\right)$ and $x^{o}=\mu_{x}, y^{o}=\mu_{y}$ the average input and output vectors, respectively, computed over all observations. These shadow price vectors can easily be determined from the optimal solution of the corresponding dual LP problems.

Obviously, these choices simplify computations since only two LPs (i.e., those determining the shadow price vectors) need to be solved for finding all possible F-P indexes. But then, all F-P indexes depend on these same two shadow price vectors. If one or more of the components of these vectors vanish, then possible changes in the corresponding inputs or outputs are not captured in any of the F-P indexes. Moreover, questions can be raised as to what extent these additional assumptions and choices are realistic when applied on nonparametric technologies.

As a matter of fact, quite a bit of the currently published studies using the F-P index take the above shortcut. ${ }^{6}$ To our knowledge, from the above mentioned empirical studies this is the case for Arjomandi, Harvie, and Valadkhani (2012), Chancellor and Abbott (2015), Islam, Xayavong, and Kingwell (2014), Molinos-Senante, Maziotis, and Sala-Garrido (2017), Nguyen and Simioni (2015), Rahman and Salim (2013), among others.

Therefore, it seems important to explicitly test whether the simplified F-P TFP index (4) in fact provides a good approximation to the true F-P TFP index (3). To the best of our knowledge, such a test has not yet been offered in the literature.

\footnotetext{
${ }^{5}$ Note that this condition is only of relevance if distance functions are measured with respect to technologies varying over time. Since all distance functions in the empirical application of this article are computed with respect to the same overall technology, this assumption is irrelevant here.

${ }^{6}$ We know when the the authors explicitly state that they use the DPIN software to compute the F-P indexes. Obviously, sometimes the use of the DPIN software may well not be explicitly mentioned.
} 


\subsection{Färe-Primont Productivity Index: Sub-vector Specifications}

Continuing from the general framework of Section 3.1, the F-P TFP index is interpreted as a synthetic regional policy effectiveness index in this contribution since it evaluates the performance of regional outlays in contributing to foster economic activity. However, for the purpose of gauging the performance in promoting tourism activity in particular, we can define a sub-vector F-P output quantity index focusing on changes in the tourism component in the output vector. Partitioning the output vector into a sub-vector of fixed $\left(y_{f}\right)$ and variable outputs $\left(y_{v}\right)$, the sub-vector F-P output quantity index is defined as follows:

$$
\operatorname{FPO}\left(x^{o}, y_{v}^{k}, y_{f}^{k}, y_{v}^{l}, y_{f}^{l}\right)=\frac{D_{o}\left(x^{o}, y_{v}^{l}, y_{f}^{l}\right)}{D_{o}\left(x^{o}, y_{v}^{k}, y_{f}^{k}\right)}
$$

It is based upon output distance functions seeking to expand only the sub-vector of variable outputs as much as possible proportionally while staying within $P(x)$. In addition, if we pay attention to the input vector side, it is possible to define similarly a more general sub-vector F-P input quantity index assuming the presence of both variable and fixed input sub-vectors: ${ }^{7}$

$$
\operatorname{FPI}\left(x_{v}^{k}, x_{f}^{k}, x_{v}^{l}, x_{f}^{l}, y^{o}\right)=\frac{D_{i}\left(x_{v}^{l}, x_{f}^{l}, y^{o}\right)}{D_{i}\left(x_{v}^{k}, x_{f}^{k}, y^{o}\right)}
$$

Combining these possibilities, the ratio of this sub-vector F-P output quantity index over the subvector F-P input quantity index yields the desired sub-vector F-P TFP index or synthetic index of tourism effectiveness:

$$
\operatorname{FP}\left(x^{o}, y^{o}, x_{v}^{k}, x_{f}^{k}, y_{v}^{k}, y_{f}^{k}, x_{v}^{l}, x_{f}^{l}, y_{v}^{l}, y_{f}^{l}\right)=\frac{\operatorname{FPO}\left(x^{o}, y_{v}^{k}, y_{f}^{k}, y_{v}^{l}, y_{f}^{l}\right)}{\operatorname{FPI}\left(x_{v}^{k}, x_{f}^{k}, x_{v}^{l}, x_{f}^{l}, y^{o}\right)}
$$

This last definition of the sub-vector F-P TFP index can be useful if the technology corresponding to the analyzed sector shows the need for distinguishing between variable and fixed inputs needed to produce variable and fixed outputs. This is exactly our case under study: we are interested in the tourism activity while the tourism output requires the consumption of specific inputs and other non-specific inputs corresponding to both the public and private sector.

It follows directly from the definitions that the F-P TFP indexes (3) and (7) are transitive. Hence, in an empirical application, one can select one particular observation as the base for comparison when comparing two observations $k$ and $l .8$ The efficiencies relative to the corresponding

\footnotetext{
${ }^{7}$ Note that the sub-vector F-P indices (5) and (6) need no longer satisfy linear homogeneity which is listed by Balk (2008, pp. 58-59) as one of the favourable index properties. To overcome this issue, one could opt for choosing a reference fixed input-output combination. However, this would then require making an additional choice on top of those for the reference input-output combination $\left(x^{o}, y^{o}\right)$ and the base observation.

${ }^{8}$ Note that this base observation for comparison need not be related to the choice of the reference input-output
} 
general nonparametric, deterministic frontier technologies imposing variable returns to scale needed for determining the components of the F-P TFP indexes can be obtained by solving a series of simple linear programming problems for the observations involved (see the Appendix for details). ${ }^{9}$

\section{Empirical Specification: Regions and Tourism Activity in Europe}

The tourism industry is a significant sector for European countries. According to the World Tourism Organization (2010), the direct employment of the tourism sector varies from $3 \%$ in France to $5.1 \%$ in Spain (e.g., $4.7 \%$ in Germany), while the contribution of the tourism sector to the Total Value Added represents 3.2\% in Germany and 6.4\% in Spain (e.g., $4 \%$ in France). However, these percentages underestimate the internal relevance of the sector in each country, as the tourism coverage ratio (i.e., the ratio of inbound over outbound tourism expenditure) goes from $50.5 \%$ in Germany to $261 \%$ in Spain (e.g., $134.6 \%$ in France). These figures clearly indicate that, apart from the significant variation, the importance of tourism in terms of aggregate macroeconomic magnitudes is more substantial for the whole national economy in certain countries.

As already mentioned, our interest here is to assess the effectiveness of the tourism industry in European regions (a precedent on the assessment of efficiency in European regions is Athanassopoulos (1996)). This requires the definition of the input and output dimensions to be considered and also the justification of how these dimensions can be operationalized via a specification of technology. For these requirements, the Conceptual Framework defined for the programme 'Destination Management', proposed by the World Tourism Organization -a specialized agency of the United Nations- guides our approach. ${ }^{10}$ As can be seen on Figure 1, the fundamental unit of this conceptualization is the Tourism Destination: "a physical space in which a visitor spends at least one overnight ... it includes tourism products such as support services and attractions, and tourism resources within one days return travel time." It should be added that alternative and much more complete conceptual frameworks summarising all potentially relevant dimensions of destination competitiveness and the ensuing challenges for management and policies are available in the literature (good examples include Dwyer and Kim (2003) and Ritchie and Crouch (2003)). Therefore, our choice for the simplified UNWTO framework only intends to offer a first approximation to a more complete model of destination competitiveness.

At both regional and national levels, the Tourism Destinations are effective when these attract a high number of visitors at tourist accommodation establishments (north of the Conceptual Framework diagram, and our first output, $y_{1}$ ). Depending on their perception about the level of services and attractions provided, these visitors can spend more or less time on the Tourism Destination.

combination $\left(x^{o}, y^{o}\right)$.

${ }^{9}$ Hulten (2001) stresses that TFP measurement need not invoke the hypothesis of constant returns to scale.

${ }^{10}$ This Conceptual Framework of the UNWTO was defined on December 2002 and was found on the following web page: http://destination.unwto.org/es/node/27679 [Accessed: December 30th, 2013]. 
Figure 1: Destination Management: Conceptual Framework

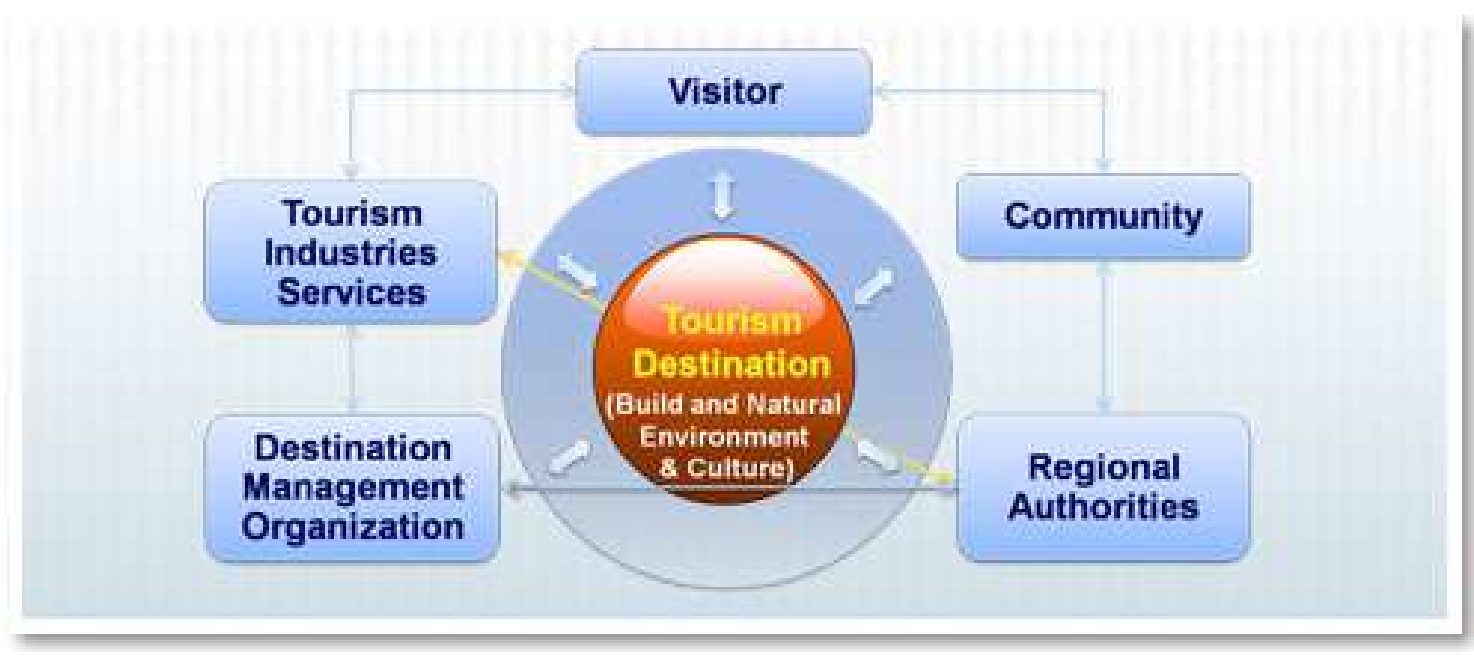

Source: United Nations World Tourism Organization (UNWTO) http://destination. unwto.org/en/content/conceptual-framework-0

(Accessed: December 30th, 2013)

This time dimension is captured by our second output variable: the total number of nights spent on the Tourism Destination $\left(y_{2}\right) .{ }^{11}$ The visitors perception depends on a number of tangible (e.g., natural and historical environment, transportation and accommodation facilities, etc.) as well as intangible attributes (e.g., culture, identity, friendliness). In the process of refining these tangible and intangible attributes to attract more visitors and to extend their stays, concerted efforts from both public and private organisms are required. On the one hand, community and regional authorities (representing the stakeholders appearing on the west side of the Conceptual Framework) deploy efforts to make sure infrastructures (in our approach, kilometres (kms.) of motorways and kms. of railways) provide means for convenient modes of transportation. ${ }^{12}$ On the other hand, private sector organizations, appearing on the east side of the Conceptual Framework, invest resources and contract employees (in our model the number of beds provided by hotels, holiday and other short-stay accommodation services and the total number of workers on retail trade, hotels and restaurants and transportation) to provide competitive services to visitors.

\footnotetext{
${ }^{11}$ In many studies on tourism productivity one of the outputs are sales (or some variations: e.g., value added). Examples include Assaf and Agbola (2011), Barros, Peypoch, and Solonandrasana (2009), and Yu and Chen (2016), among others. We refrain from doing so because primal productivity indices are in principle based on the estimation of the production technology based on physical inputs and outputs. By employing value terms we also invoke prices and this may lead to biases in the estimation of primal productivity change if there would be allocative inefficiencies.

${ }^{12}$ Our proposal is in line with Aschauer (1989) who considers the importance of public infrastructure investment (highways, streets, water systems ) when assessing the role the government plays in fostering economic growth and productivity improvement. Another precedent is Beeson and Husted (1989) who find that considerable variations of regional efficiency in the United States depend on the levels of urbanization. Puig-Junoy (2001) also finds that technical efficiency in U.S. states is positively correlated with the proportion of public capital devoted to highways. Finally, Marrocu and Paci (2011), after the estimation of a Cobb-Douglas production function, find that good transportation infrastructures increase the performance of tourism at the European regional level.
} 
Collaboration between both public and private organisms is imperative in the extremely competitive tourism industry (represented by the arrows connecting east and west sides of the diagram in Figure 1). This necessary collaboration has been stressed in the existing empirical research on tourism at the regional level (e.g., Otgaar (2012)). However, the reality is that the strategic decisions are most often taken autonomously within each sector, whereby the decisions and efforts made or planned by the other party are exogenous. This is the reason why we add fixed -non-discretionary- inputs in the effectiveness model representing the decisions taken by the other party. Summing up, from this Conceptual Framework two dimensions of effectiveness are defined depending on the unit of analysis considered.

The inputs and outputs retained in the specification of the synthetic regional policy effectiveness index can now be summarised as follows:

Outputs:

- $y_{1}$ : \# of visitors at tourist accommodation establishments.

- $y_{2}$ : \# of nights spent by visitors at tourist accommodation establishments.

Inputs:

- $x_{1}$ : \# of beds provided by hotels, holiday and other short-stay accommodation services.

- $x_{2}$ : \# of workers on retail trade, hotels and restaurants and transportation.

- $x_{3}$ : kms. of motorways.

- $x_{4}$ : kms. of railways.

The status of these four inputs varies according to whether one takes a private or public sector viewpoint. From the regional private sector point of view, its synthetic index of effectiveness on the tourism industry considers the first two input variables as variable (i.e., $x_{1}$ and $x_{2}$ ) while the last two inputs are fixed (i.e., $x_{3}$ and $x_{4}$ ). By contrast, from the regional public sector point of view, its synthetic index of effectiveness of the tourism industry takes the first two input variables as fixed while the last two are variable dimensions. Remark that the discretionary public sector variables are probably slower to change than the discretionary private sector variables. This may imply that both synthetic subindices of effectiveness operate on a somewhat different time scale.

We are unaware of similar models in the literature to represent the complementarities of public and private sector inputs in generating joint outputs. For instance, Karkazis and Thanassoulis (1998) rather specify public investment amounts and incentives as inputs to attract private sector investments in the agricultural, industrial and service sectors as outputs. The Cracolici, Nijkamp, and Rietveld (2008) article that assesses the performance of Italian regions in a single year has 
the following specification. The single output bed-nights relative to population is related to the following proxies for cultural and historical capital, human capital, and labour inputs: the regional state-owned cultural patrimony and heritage (number of museums, monuments and archaeological sites) standardized for population; tourist school graduates divided by working age population; and the labour units employed in the tourism sector divided by the total regional labour units. Instead we opt for a double output specification and we focus on two public infrastructure inputs rather than state-owned cultural patrimony and heritage as single input.

To illustrate the F-P synthetic index of effectiveness, regional tourism statistics from Eurostat (European Union) were collected. A total of 112 units (defined by Eurostat as 'Nomenclature of Territorial Units for Statistics' (NUTS) providing a uniform breakdown of territorial units for the production of regional statistics for the European Union) were included in the sample. ${ }^{13}$ The list of countries and the NUTS units included (between brackets) are: Austria (1), Belgium (1), Czech Republic (8), Croatia (2), Estonia (3), Finland (3), France (29), Germany (1), Hungary (8), Lithuania (3), Netherlands (1), Poland (12), Romania (8), Slovenia (5), Spain (24), Sweden (1) and UK (2). Note that data for some countries (e.g., Italy, Greece and Denmark) are simply unavailable. Furthermore, the sample includes counties, departments, districts, provinces, regions or states. Thus, these regions are rather heterogeneous in terms of size. To mitigate the effect of size differences, we opt for a variable returns to scale specification when computing the distance functions entering the F-P synthetic index. While these data may raise some questions in terms of the homogeneity of the sample, these are the only available data at Eurostat.

With regards to the time period considered, three years have been selected with a constant time interval of four years: 2003, 2007 and 2011. This choice allows the comparison of the effectiveness index comparing two different time periods: (1) the period 2003-2007 when the European economy delivered a global growth; and (2) the period 2007-2011 characterized by the recession and the financial crisis. ${ }^{14}$ Accordingly, one can expect that in the first time period growth in the effectiveness index should be the most prevalent situation, while in the second time period adjustments may be necessary to face the effects caused by the economic crisis. Furthermore, this choice of a four year time interval is also related to the fact that the discretionary public sector variables are likely to change rather slowly over time (see supra).

Table 1 contains the descriptive statistics corresponding to the above-mentioned input and output variables in three panels corresponding to each of the three years. It is possible to make the following observations on Table 1. First, comparing the values per variable, there is clear evidence of significant differences in the size. Again, this is the reason for choosing variable returns to scale

\footnotetext{
${ }^{13}$ Data are taken from general and regional statistics of Eurostat: see the web pages http://epp.eurostat.ec.europa.eu/portal/page/portal/statistics/themes.

${ }^{14} \mathrm{As}$ an alternative research strategy, one could investigate other exogenous shocks. One example could be terrorist attacks: these may have transitory or permanent effects on tourism in a particular region (e.g., Paris or London) or even at the country level (e.g., France or the UK)). This could inspire future work.
} 
as the most adequate specification of technology. ${ }^{15}$

Table 1: Descriptive Statistics of the Inputs and Outputs Defining the Effectiveness Indices

Panel a: Descriptive Statistics for 2003

\begin{tabular}{crrrrrr}
\hline & Mean & Min. & Quartile 1 & Median & Quartile 3 & Max. \\
\hline Visitors & 8663687 & 166503 & 1062404 & 2455282 & 7500214 & 116021323 \\
Nights & 26499851 & 410415 & 3084433 & 6595206 & 24478128 & 342540544 \\
Beds & 344867 & 6981 & 41772 & 98482 & 373682 & 5579023 \\
Employees & 624 & 28 & 141 & 239 & 547 & 8243 \\
Motorways-km & 830 & 0 & 90 & 328 & 682 & 12044 \\
Railways-km & 3119 & 0 & 969 & 1561 & 2670 & 43793 \\
\hline
\end{tabular}

Panel b: Descriptive Statistics for 2007

\begin{tabular}{crrrrrr}
\hline & Mean & Min. & Quartile 1 & Median & Quartile 3 & Max. \\
\hline Visitors & 10065856 & 218663 & 1472130 & 3079533 & 9453787 & 127674245 \\
Nights & 28885037 & 584917 & 3414120 & 6804154 & 24705724 & 381912458 \\
Beds & 363616 & 7891 & 44797 & 103513 & 393116 & 5736966 \\
Employees & 688 & 32 & 155 & 295 & 634 & 8929 \\
Motorways-km & 960 & 0 & 130 & 371 & 908 & 13013 \\
Railways-km & 3057 & 0 & 956 & 1589 & 2660 & 38005 \\
\hline
\end{tabular}

Panel c: Descriptive Statistics for 2011

\begin{tabular}{crrrrrr}
\hline & Mean & Min. & Quartile 1 & Median & Quartile 3 & Max. \\
\hline Visitors & 10857221 & 241554 & 1464204 & 3336024 & 10031267 & 148791996 \\
Nights & 31632895 & 568663 & 3482645 & 7214671 & 31932296 & 401006928 \\
Beds & 355358 & 8213 & 47512 & 92062 & 382211 & 5014118 \\
Employees & 648 & 28 & 148 & 272 & 580 & 8793 \\
Motorways-km & 1040 & 0 & 158 & 385 & 1013 & 14555 \\
Railways-km & 3109 & 0 & 1018 & 1607 & 2672 & 41846 \\
\hline
\end{tabular}

Second, paying attention to the temporal path, it is curious to see how the effect of the crisis does not appear to be significant on the output side, since both the number of visitors and nights exhibit a consistent growth over the years. This path is evident not only in the values corresponding to the arithmetic mean or the median, but also in the majority of the quartiles. However, another trend appears on the side of private inputs, where both the number of beds and employees experience a drop in 2011 with regard to the existing values in 2007. Comparing these different time paths, the immediate question we face is how this diverging evolution can be explained? A direct answer is related to the variation in capacity utilisation. Thus, paying attention to the second column of Table 1 (the arithmetic mean), dividing the number of nights by the number of beds provides an estimation of the average number of days that beds are occupied. This ratio reflects a simple occupancy ratio: it indicates that each bed is in use 76 days $(26,499,851 / 344,867)$ in 2003 , 79 days

\footnotetext{
${ }^{15}$ Many contributions to efficiency analysis in the tourism sector impose flexible or variable returns to scale (see, e.g., Pulina, Detotto, and Paba (2010)).
} 
$(28,885,037 / 363,616)$ in 2007 and $89(31,632,895 / 355,358)$ days in 2011. Summing up, there clearly seems some tendency to reduce the number of beds offered after the crisis to control for what seems to be perceived as an excessive capacity.

The inputs corresponding to the public sector are far more difficult to adjust. These inputs tend to increase when outputs grow at a positive rate, but are difficult to reduce when these same outputs experience a negative growth rate. In accounting terms, this situation is said to generate "sticky costs". In this framework, the evolution from the year 2007 to 2011 in Table 1 confirms that public infrastructures always generate sticky costs (contrarily to what happen in the inputs from private sectors). Thus, one may expect that the public sector F-P effectiveness index tends to deteriorate over time compared to the one corresponding to the private sector, especially in the period of financial crisis.

Since the F-P productivity indexes (3) and (7) are transitive, any observation can be set as base observation. ${ }^{16}$ A post-optimization change in basis can simply be realized by multiplying with the appropriate factor without having the need of optimizing again. For the empirical study in Section 5, the basis is set to the region of Paris as the capital of France attracting the highest number of tourists. In particular, we use the first year (i.e., 2003) present in the data base for this basis.

\section{Empirical Illustration: Results}

Empirical results for the general F-P index (3) and for its two sub-vector variations based on (7) offering a complementary perspective are listed in Table 2. As explained before, a fixed inputoutput combination $\left(x^{o}, y^{o}\right)$ needs to be set in the computations. If the suggestion by O'Donnell (2014) of taking the average inputs and outputs over all regions and time periods is followed, then infeasibilities occur for those regions having zero inputs. This observation follows from the inability of the input directional distance function of up-scaling these zero inputs to a level that allows producing sufficient outputs. Note that these problems do not occur when all inputs are non-zero. Unfortunately, the data we use contain zeros in the input variables $x_{3}$ and $x_{4}$ for several regions. To avoid these infeasibilities, the fixed input-output combination $\left(x^{o}, y^{o}\right)$ is set to the maximum of all inputs and the minimum of all outputs, respectively. This choice can be considered as being optimistic since the input efficiencies are now measured for each observation assuming that it only needs to supply the minimal outputs observed in the data. Similarly, output efficiencies are now measured assuming that the observation can use the maximal possible inputs available in the data. $^{17}$

\footnotetext{
${ }^{16}$ Note that this base observation should not be mixed-up with the fixed reference combination $\left(x^{o}, y^{o}\right)$ mentioned earlier.

${ }^{17}$ With the choices made, no infeasibilities are observed in the computations. However, it remains an open question whether or not infeasibilities can occur in general and to what extent the choice of the reference input-output combination influences the occurrence of infeasibilities. We reserve these issues for future research.
} 
Panel a reports summarizing statistics for the general F-P index (3), i.e., without making a distinction between fixed and variable inputs. Panels b and c present similar statistics for the F-P indexes (7) considering the private and public sector, respectively. As commented in Section 4 and confirmed by Figure 1, the natural and historical environment, among others, have a decisive influence to attract touristic activity. These characteristics provide essential competitive strengths but are extremely difficult to adjust in the short term. According to this reasoning, regions with a competitive advantage ceteris paribus can be more effective than regions with weak competitive resources. However, a good management, both on the side of the public and the private sectors, is required to convert these resources into a substantial advantage and to obtain a good score on the effectiveness index. To separate regions according to their initial competitive advantage, we take data from the tourism competitiveness reports of the World Economic Forum (see Blanke and Chiesa $(2007,2011)$ ). We characterize regions depending on their position with respect to the median of European regions regarding the existing human, cultural and natural resources: regions above the median score are taken as competitive and countries below the median are considered as non-competitive. Observe the further distinction between these competitive and non-competitive regions in panels a, b and c of Table 2 .

For comparison, the special F-P index (4) is reported in Table 3. Panel a provides the results obtained when choosing for the fixed reference input-output combination $\left(x^{o}, y^{o}\right)$ the average inputs and outputs, respectively, computed over all regions and time periods. This is the choice used by the software DPIN by O'Donnell (2011a). Panel b reports similar statistics for the F-P indexes obtained from setting $x^{o}$ and $y^{o}$ equal to the maximum of all inputs and the minimum of all outputs, respectively. This is the same choice as the one used in Table 2, thus allowing some comparison.

Summarising the main tendencies in both Tables 2 and 3 leads to the following conclusions. First, from a global perspective one cannot but observe on average a low productivity compared to the Paris region. Second, competitive regions have a slightly higher TFP level than non-competitive regions. Third, few observations do better than Paris in the total sample and among the competitive regions, while no region beats Paris among the non-competitive regions. Fourth, the interquartile range widens a bit in 2011, perhaps reflecting an impact of the financial crisis.

For the private and public sector viewpoints, almost the same conclusions emerge. One exception is that somewhat more observations do better than Paris from a public sector viewpoint, even among the non-competitive regions. Also for the two special F-P indices, the same conclusions hold true. One can just observe somewhat lower TFP levels relative to the Paris region compared to the general F-P index.

The complete distributions of the F-P effectiveness index for the total sample (panel a in Table 2) solely are displayed in the boxplots of Figure 2. Recall that a boxplot displays a five-number summary containing the minimum, the lower hinge, the median, the upper hinge, and the maximum. The length of the box between both hinges represents the interquartile range, while the horizontal 
Table 2: Distribution of the General F-P Effectiveness Indexes

Panel a: Global viewpoint based on (3)

\begin{tabular}{rrrrrrrrrr}
\hline & Year & Count $\geq 1$ & Count $<1$ & Mean & Min & Q1 & Q2 & Q3 & Max \\
\hline Total sample & 2003 & 4 & 108 & 0.432 & 0.049 & 0.173 & 0.254 & 0.359 & 9.133 \\
& 2007 & 4 & 108 & 0.430 & 0.061 & 0.183 & 0.247 & 0.377 & 8.526 \\
& 2011 & 4 & 108 & 0.435 & 0.068 & 0.163 & 0.246 & 0.420 & 8.622 \\
\hline Competitive & 2003 & 4 & 79 & 0.504 & 0.049 & 0.193 & 0.276 & 0.407 & 9.133 \\
& 2007 & 4 & 79 & 0.504 & 0.061 & 0.199 & 0.269 & 0.411 & 8.526 \\
& 2011 & 4 & 79 & 0.514 & 0.068 & 0.193 & 0.284 & 0.444 & 8.622 \\
\hline Non-competitive & 2003 & 0 & 29 & 0.224 & 0.066 & 0.160 & 0.212 & 0.275 & 0.592 \\
& 2007 & 0 & 29 & 0.220 & 0.077 & 0.130 & 0.206 & 0.274 & 0.417 \\
& 2011 & 0 & 29 & 0.210 & 0.069 & 0.128 & 0.162 & 0.263 & 0.429 \\
\hline
\end{tabular}

Panel b: Private sector viewpoint based on (7)

\begin{tabular}{rrrrrrrrrr}
\hline & Year & Count $\geq 1$ & Count $<1$ & Mean & Min & Q1 & Q2 & Q3 & Max \\
\hline Total sample & 2003 & 4 & 108 & 0.549 & 0.053 & 0.172 & 0.242 & 0.400 & 16.479 \\
& 2007 & 4 & 108 & 0.416 & 0.075 & 0.177 & 0.237 & 0.409 & 7.416 \\
& 2011 & 5 & 107 & 0.406 & 0.071 & 0.167 & 0.251 & 0.380 & 6.814 \\
\hline Competitive & 2003 & 4 & 79 & 0.651 & 0.066 & 0.184 & 0.241 & 0.409 & 16.479 \\
& 2007 & 4 & 79 & 0.470 & 0.102 & 0.191 & 0.236 & 0.415 & 7.416 \\
& 2011 & 5 & 78 & 0.464 & 0.075 & 0.195 & 0.262 & 0.409 & 6.814 \\
\hline Non-competitive & 2003 & 0 & 29 & 0.257 & 0.053 & 0.146 & 0.293 & 0.358 & 0.497 \\
& 2007 & 0 & 29 & 0.261 & 0.075 & 0.131 & 0.252 & 0.356 & 0.518 \\
& 2011 & 0 & 29 & 0.241 & 0.071 & 0.117 & 0.167 & 0.288 & 0.659 \\
\hline
\end{tabular}

Panel c: Public sector viewpoint based on (7)

\begin{tabular}{rrrrrrrrrr}
\hline & Year & Count $\geq 1$ & Count $<1$ & Mean & Min & Q1 & Q2 & Q3 & Max \\
\hline Total sample & 2003 & 20 & 92 & 1.212 & 0.187 & 0.436 & 0.622 & 0.839 & 34.857 \\
& 2007 & 18 & 94 & 1.173 & 0.200 & 0.439 & 0.597 & 0.824 & 32.373 \\
& 2011 & 19 & 93 & 1.134 & 0.194 & 0.435 & 0.659 & 0.883 & 32.882 \\
\hline Competitive & 2003 & 15 & 68 & 1.420 & 0.187 & 0.478 & 0.610 & 0.835 & 34.857 \\
& 2007 & 15 & 68 & 1.372 & 0.218 & 0.478 & 0.604 & 0.789 & 32.373 \\
& 2011 & 17 & 66 & 1.338 & 0.241 & 0.514 & 0.689 & 0.913 & 32.882 \\
\hline Non-competitive & 2003 & 5 & 24 & 0.617 & 0.192 & 0.288 & 0.661 & 0.847 & 1.236 \\
& 2007 & 3 & 26 & 0.602 & 0.200 & 0.306 & 0.556 & 0.880 & 1.135 \\
& 2011 & 2 & 27 & 0.549 & 0.194 & 0.260 & 0.450 & 0.804 & 1.264 \\
\hline
\end{tabular}


Table 3: Distribution of the Special F-P Effectiveness Indexes

Panel a: Global viewpoint based on (4) with DPIN-Mu (i.e., $\left.\left(x^{o}, y^{o}\right)=\left(\mu_{x}, \mu_{y}\right)\right)$

\begin{tabular}{rrrrrrrrrr}
\hline & Year & Count $\geq 1$ & Count $<1$ & Mean & Min & Q1 & Q2 & Q3 & Max \\
\hline Total sample & 2003 & 4 & 108 & 0.463 & 0.102 & 0.292 & 0.458 & 0.598 & 1.288 \\
& 2007 & 4 & 108 & 0.496 & 0.135 & 0.304 & 0.496 & 0.643 & 1.267 \\
& 2011 & 4 & 108 & 0.566 & 0.141 & 0.308 & 0.573 & 0.759 & 1.304 \\
\hline Competitive & 2003 & 4 & 79 & 0.528 & 0.117 & 0.412 & 0.515 & 0.647 & 1.288 \\
& 2007 & 4 & 79 & 0.558 & 0.135 & 0.437 & 0.534 & 0.667 & 1.267 \\
& 2011 & 4 & 79 & 0.643 & 0.157 & 0.464 & 0.664 & 0.785 & 1.304 \\
\hline Non-competitive & 2003 & 0 & 29 & 0.280 & 0.102 & 0.182 & 0.257 & 0.338 & 0.598 \\
& 2007 & 0 & 29 & 0.320 & 0.145 & 0.191 & 0.286 & 0.363 & 0.659 \\
& 2011 & 0 & 29 & 0.347 & 0.141 & 0.193 & 0.285 & 0.400 & 0.757 \\
\hline
\end{tabular}

Panel b: Global viewpoint based on (4) with DPIN-Max (i.e., $\left.\left(x^{o}, y^{o}\right)=(\max (x), \min (y))\right)$

\begin{tabular}{rrrrrrrrrr}
\hline & Year & Count $\geq 1$ & Count $<1$ & Mean & Min & Q1 & Q2 & Q3 & Max \\
\hline Total sample & 2003 & 4 & 108 & 0.333 & 0.056 & 0.193 & 0.278 & 0.386 & 2.125 \\
& 2007 & 4 & 108 & 0.349 & 0.069 & 0.204 & 0.281 & 0.427 & 2.173 \\
& 2011 & 5 & 107 & 0.374 & 0.078 & 0.199 & 0.280 & 0.456 & 2.329 \\
\hline Competitive & 2003 & 4 & 79 & 0.375 & 0.056 & 0.226 & 0.310 & 0.432 & 2.125 \\
& 2007 & 4 & 79 & 0.389 & 0.069 & 0.233 & 0.321 & 0.452 & 2.173 \\
& 2011 & 5 & 78 & 0.424 & 0.078 & 0.242 & 0.346 & 0.498 & 2.329 \\
\hline Non-competitive & 2003 & 0 & 29 & 0.214 & 0.057 & 0.137 & 0.214 & 0.296 & 0.451 \\
& 2007 & 0 & 29 & 0.232 & 0.092 & 0.134 & 0.195 & 0.293 & 0.504 \\
& 2011 & 0 & 29 & 0.232 & 0.081 & 0.135 & 0.182 & 0.292 & 0.585 \\
\hline
\end{tabular}


line in the centre marks the median. The length of the whiskers denoting the range is here drawn no longer than 1.5 times the length of the box. The first three boxplots compare the F-P effectiveness indices in general (denoted Global) and for the private and public sector (denoted Private and Public respectively). The last two boxplots do the same for the special F-P index (4) from Table 3 panel a (denoted DPIN-Mu) and panel b (denoted DPIN-Max).

Three observations stand out. First, the F-P effectiveness indices for the private and public sector seem to be markedly different. Second, also the F-P effectiveness index in general compared to the special F-P indices seem to be markedly different. Third, both the position of the median within the box and the relative length of both whiskers suggest skewed distributions for all F-P effectiveness indices.

In Table 4, we present the results of a variety of hypothesis tests on the distributional changes in the F-P effectiveness index using a Li (1999) test statistic. ${ }^{18}$ This nonparametric test analyzes the differences between entire distributions and does not focus exclusively on first moments (e.g., the Wilcoxon signed-ranks test). It tests the statistical significance of differences between two kernel-based estimates of density functions, $f$ and $g$, of a random variable $x$. The null hypothesis is contrasted as follows: $H_{0}$ is: $f(x)=g(x)$ for all $x$, while the alternative hypothesis is $H_{1}$ : $f(x) \neq g(x)$ for some $x$. This test is valid for both dependent and independent variables: observe that dependency is a characteristic of frontier estimators (i.e., efficiency levels depend on sample size, among others). For this test statistic, we report on the conventional $1 \%$ significance level. In panel a we test for the eventual differences in productivity among general (3) and private and public sector (7) productivity for a given time period (first three lines), and the eventual differences in productivity among the general (3) and the two special variations (4) for a given time period (last three lines). The time periods considered are all years confounded (first column) and each of the three years on its own (second to fourth columns). The next five lines compare each of the general, private and public sector, and the two special variations of productivity comparing the years 2003 to 2007 (first column) and 2007 to 2011 (second column). In panels b and c, we test for exactly the same differences in productivity (but ignoring the two special variations (4)) between competitive and non-competitive conditions respectively. In panel $d$, we finally test for exactly the same productivity differences by contrasting competitive and non-competitive conditions.

In panel a of Table 4, we can make the following observations. First, general (3) and private sector (7) productivity share a common distribution, as was already apparent from the boxplots in Figure 2. Second, general (3) and public sector (7) productivity as well as private and public sector (7) productivity follow different distributions. Third, general (3) productivity and its two special variations (4) are clearly different, though in one case (i.e., DPIN-Max) this conclusion is not valid when focusing on the years 2003 or 2007 separately. The unavoidable conclusion is that for our sample the additional assumptions on technology needed to obtain the special index (4) are invalidated. When comparing two by two over the years, all distributions are similar, except for

\footnotetext{
${ }^{18}$ This test statistic has an improved variance estimator compared to Li (1996).
} 
Figure 2: Boxplots of the Effectiveness Index for the Total Sample

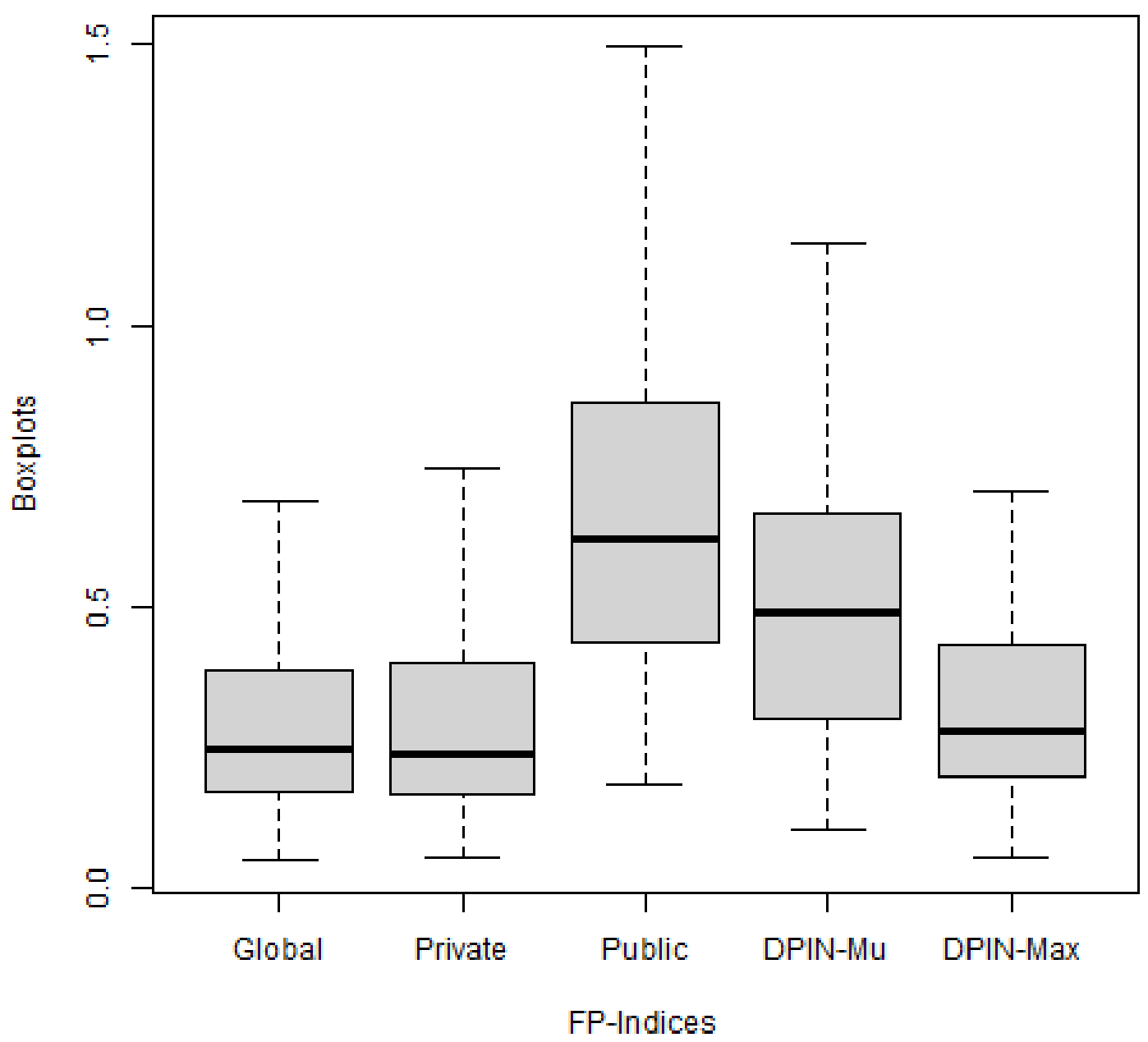


Table 4: Nonparametric Hypothesis Tests $\dagger$

Panel a: Complete Sample

\begin{tabular}{|c|c|c|c|c|}
\hline Null hypothesis $\left(H_{0}\right)$ & All periods & 2003 & 2007 & 2011 \\
\hline Global vs. Private & $\neg-$ Rej. $^{\star}$ & $\neg$-Rej. & $\neg$-Rej. & $\neg$-Rej \\
\hline Global vs. Public & $\operatorname{Rej}^{\ddagger}$ & Rej. & Rej. & Rej. \\
\hline Private vs. Public & Rej. & Rej. & Rej. & Rej. \\
\hline Global vs. DPIN-Mu & Rej. & Rej. & Rej. & Rej. \\
\hline Global vs. DPIN-Max & Rej. & $\neg$-Rej. & $\neg$-Rej. & Rej. \\
\hline & 2003 vs. 2007 & 2007 vs. 2011 & & \\
\hline Global & ᄀ-Rej. & $\neg$-Rej. & & \\
\hline Private & $\neg$-Rej. & $\neg$-Rej. & & \\
\hline Public & $\neg$-Rej. & $\neg$-Rej. & & \\
\hline DPIN-Mu & $\neg$-Rej. & Rej. & & \\
\hline DPIN-Max & $\neg$-Rej. & $\neg$-Rej. & & \\
\hline
\end{tabular}

Panel b: Regions With Competitive Resources

\begin{tabular}{|c|c|c|c|c|}
\hline Null hypothesis $\left(H_{0}\right)$ & All periods & 2003 & 2007 & 2011 \\
\hline Global vs. Private & $\neg$-Rej. & $\neg$-Rej. & $\neg$-Rej. & $\neg$-Rej. \\
\hline Global vs. Public & Rej. & Rej. & Rej. & Rej. \\
\hline Private vs. Public & Rej. & Rej. & Rej. & Rej. \\
\hline & 2003 vs. 2007 & 2007 vs. 2011 & & \\
\hline Global & $\neg$-Rej. & ᄀ-Rej. & & \\
\hline Private & $\neg$-Rej. & $\neg$-Rej. & & \\
\hline Public & $\neg$-Rej. & $\neg$-Rej. & & \\
\hline
\end{tabular}

Panel c: Regions Without Competitive Resources

\begin{tabular}{|c|c|c|c|c|}
\hline Null hypothesis $\left(H_{0}\right)$ & All periods & 2003 & 2007 & 2011 \\
\hline Global vs. Private & Rej. & Rej. & $\neg$-Rej. & $\neg$-Rej. \\
\hline Global vs. Public & Rej. & Rej. & Rej. & Rej. \\
\hline Private vs. Public & Rej. & Rej. & Rej. & Rej. \\
\hline & 2003 vs. 2007 & 2007 vs. 2011 & & \\
\hline Global & $\neg$-Rej. & Rej. & & \\
\hline Private & $\neg$-Rej. & $\neg$-Rej. & & \\
\hline Public & $\neg$-Rej. & $\neg$-Rej. & & \\
\hline
\end{tabular}

Panel d: Competitive vs. Non-Competitive

\begin{tabular}{lcccc}
\hline Null hypothesis $\left(H_{0}\right)$ & All periods & 2003 & 2007 & 2011 \\
\hline Global & $\neg$-Rej. & $\neg$-Rej. & $\neg$-Rej. & $\neg$-Rej. \\
Private & $\neg$-Rej. & $\neg$-Rej. & $\neg$-Rej. & $\neg$-Rej. \\
Public & $\neg$-Rej. & $\neg$-Rej. & $\neg$-Rej. & $\neg$-Rej. \\
\hline
\end{tabular}

$\dagger$ † Significance level 1-\%. ${ }^{\ddagger}$ Rej. = Reject. ${ }^{\star} \neg-$ Rej. $=$ Do not reject. 
DPIN-Mu in the years 2007 versus 2011. Thus, only one productivity indicator seems to capture a distributional variation that is potentially due to the financial crisis.

Panel b of Table 4 contains the test statistics corresponding to regions having competitive human, cultural and natural resources. In these regions, the following conclusions pertain. First, general (3) and private sector (7) productivity again share a common distribution. Second, general (3) and public sector (7) productivity as well as private and public sector (7) productivity share once more different distributions. Finally, when comparing two by two years all distributions are again similar.

Panel c of Table 4 presents the results for the regions having non-competitive resources. For these regions, the conclusions are very similar to the regions with competitive resources, except two issues. First, general (3) and private sector (7) productivity now do not share a common distribution, except for the single years 2007 and 2011. Second, when comparing two by two over the years, all distributions are similar, except for the general index between the years 2007 and 2011. This change in distribution may well reflect the financial crisis.

Panel d of Table 4 compares regions having competitive and non-competitive resources. The basic conclusion is that general, private and public sector productivity share a common distribution and cannot be distinguished.

To conclude, the most pertinent results can be summarised as follows. First, while general and private sector productivity share a common distribution, general and public sector productivity as well as private and public sector productivity follow different distributions. Second, general and the two special variations of productivity are clearly different. Third, when comparing distributions two by two over the years, there is sometimes an impact for the years 2007 compared to 2011, perhaps reflecting an effect of the financial crisis.

\section{Conclusions}

This article has proposed a synthetic regional policy effectiveness index to assess the performance of the tourism industry. Its contributions are both from the theoretical and on the empirical application point of view.

From the theoretical side, the proposed F-P TFP index is less known and is of relatively recent date, and has been far less applied than the Malmquist index. But, some of its properties have advantages to suggest its use. First, while most traditional multilateral and even partial productivity indices use average practice technologies (e.g., McMahon (1994) or Blake, Sinclair, and Soria (2006)), the utilisation of distance functions in combination with explicit best practice technologies under minimal assumptions capable to handle multiple inputs and outputs leads to the use of endogenous weights, whereby these weights are determined by the empirical configuration of the 
data in the sample. Second, the success of a region in effectively contributing to the promotion of tourism is evaluated by measuring some distance to a best practice frontier technology that serves as a common benchmark. This leads to productivity indices that do not conflate efficiency and productivity changes. Three, the choice for the F-P TFP index that normally satisfies the determinateness and transitivity properties is better than other more popular productivity indices (e.g., the Malmquist index is a case in point). Transitivity ensures that the interpretation of F-P index values is straightforward, even for non-specialists. Determinateness guarantees that the linear programs constituting the index are always feasible. Fourth, the complementary perspective by defining both a public and private F-P TFP index to evaluate the effectiveness of both the private and public sector using a common aggregate frontier technology is -to the best of our knowledgenew in the literature.

While all these properties are rather well-known, the value added of our proposal is that the F-P index has been adapted for the presence of fixed and variable outputs and inputs. Indeed, in its standard formulation the F-P index assumes a total flexibility of the outputs and inputs. However, the reality is that in the short term organizations face inflexibilities or experience adjustment costs that can make it difficult -or even impossible- to modify the observed level of certain outputs and/or inputs. Thus, researchers and practitioners interested in the assessment of the total factor productivity changes in the short term have a new tool to estimate these changes. Furthermore, the complementary specification of a public and private sector technology and the resulting F-P index is innovative. An important open issue is how the sector level index can be related to these two complementary subindices. ${ }^{19}$

Regarding the empirical application, the European tourism industry at the regional level has been analysed in three years (2003, 2007 and 2011) to determine any eventual impact of the financial crisis. Our search for an established conceptual framework led us to adopt the conceptual model for Destination Management developed by the World Tourism Organization. The starting point of this framework is that the outcome of tourism activity depends on the efforts deployed by both the public and the private sectors. This means that their collaboration is required because the non-optimal endowment of resources of one of the agents can potentially affect the performance of the other. As a consequence, two specific models to separately assess the evolution of both the private and public sectors have been implemented.

The main empirical conclusions to retain can be summarised as follows. First, the average region has a low productivity compared to the Paris region. Second, distinguishing between competitive and non-competitive regions in terms of the presence of human, cultural and natural resources, somewhat different trends are detected: first, competitive regions have higher TFP levels than non-competitive regions, and second there seem to appear minor differences in patterns related to the financial crisis. But, the distributional tests reveal that these differences between competitive

\footnotetext{
${ }^{19}$ This may call for a rather different approach abandoning radial measures in favour of nonradial measures like the directional distance function (see, e.g., Chambers (2002)).
} 
and non-competitive regions turn out to be insignificant.

Third, the general (3) and the two special variations (4) of the F-P indices are clearly different. While the additional assumptions on technology needed to obtain the special index (4) are not valid for our sample, it is recommended that further tests are done to corroborate our findings. In the meantime researchers should perhaps be prudent when using the DPIN software to obtain the special F-P indices.

Fourth, the interquartile range widens somewhat in 2011 which is probably due to the financial crisis. Thus, regions having increased their effectiveness index are difficult to catch-up, which introduces divergence in the effectiveness indices. Since our analysis only compares three years, one should avoid to overreact. But, clearly if the effectiveness index would persistently deteriorate over longer time horizons, then the implications could be that countries lacking good environmental conditions should define strategic actions, affecting all stakeholders involved, to improve their position. The strategy could consist in increasing the quality, developing new facilities, or establishing other collaborative marketing actions (reinforcing the brand image or expanding the use of information technology) to attract more visitors. When the possibilities to develop additional activities are exhausted, the adjustment in the level of resources endowed may avoid over-investment: this implies a focus on input adjustment as a tool to increase the effectiveness of the sector.

There are other important aspects one could further explore. For instance, when collecting the data we realized that the average capacity utilization in the European tourism industry remains below 25 per cent. Thus, a natural extension of this article could be double. From a theoretical point of view, one can develop an extension of the F-P effectiveness index to include the impact of changes in capacity utilization. Such an extension can also be very useful to sectors other than tourism. From the empirical point of view, it can also be interesting to observe the evolution of the effectiveness during peak demand and the impact caused by possible bottlenecks in the public infrastructures. Finally, on the technology side it may be worthwhile mentioning that it is perfectly possible to weaken the assumptions on technology (e.g., by dropping the convexity axiom as in Kerstens and Van de Woestyne (2014)).

\section{References}

Arjomandi, A., C. Harvie, and A. Valadkhani (2012): "An Empirical Analysis of Iran's Banking Performance," Studies in Economics and Finance, 29(4), 287-300.

Aschauer, D. (1989): "Is Public Expenditure Productive?," Journal of Monetary Economics, $23(2), 177-200$.

Assaf, A., And F. Agbola (2011): "Total Productivity in the Australian Hotel Industry: Estimating and Bootstrapping Malmquist Indices," Tourism Analysis, 16(3), 295-304. 
Athanassopoulos, A. (1996): "Assessing the Comparative Spatial Disadvantage (CSD) of Regions in the European Union Using Non-Radial Data Envelopment Analysis Methods," European Journal of Operational Research, 94(3), 439-452.

Atkinson, S., C. Cornwell, and O. Honerkamp (2003): "Measuring and Decomposing Productivity Change: Stochastic Distance Function Estimation versus Data Envelopment Analysis," Journal of Business 8 Economic Statistics, 21(2), 284-294.

BALK, B. (2008): Price and Quantity Index Numbers: Models for Measuring Aggregate Change and Difference. Cambridge University Press, New York.

Barros, C., N. Peypoch, and B. Solonandrasana (2009): "Efficiency and Productivity Growth in Hotel Industry," International Journal of Tourism Research, 11(4), 389-402.

Beeson, P., And S. Husted (1989): "Patterns and Determinants of Productive Efficiency in State Manufacturing," Journal of Regional Science, 29(1), 15-28.

Bjurek, H. (1996): "The Malmquist Total Factor Productivity Index," Scandinavian Journal of Economics, 98(2), 303-313.

Blake, A., M. Sinclair, And J. Soria (2006): "Tourism Productivity: Evidence from the United Kingdom," Annals of Tourism Research, 33(4), 1099-1120.

Blanke, J., and T. Chiesa (2007): "The Travel \& Tourism Competitiveness Report 2007. Furthering the Process of Economic Development," Report, World Economic Forum, Geneva.

— (2011): "The Travel \& Tourism Competitiveness Report 2011. Beyond the Downturn," Report, World Economic Forum, Geneva.

Bosetti, V., And G. Locatelli (2006): "A Data Envelopment Analysis Approach to the Assessment of Natural Parks' Economic Efficiency and Sustainability. The Case of Italian National Parks," Sustainable Development, 14(4), 277-286.

Botti, L., O. Goncalves, and H. Ratsimbanierana (2012): "French Destination Efficiency: A Mean-Variance Approach," Journal of Travel Research, 51(2), 115-129.

Bouckaert, G. (1993): "Efficiency Measurement from a Management Perspective: A Case of the Civil Registry Office in Flanders," International Review of Administrative Sciences, 59(1), 11-27.

Briec, W., And K. Kerstens (2009): "Infeasibilities and Directional Distance Functions with Application to the Determinateness of the Luenberger Productivity Indicator," Journal of Optimization Theory and Applications, 141(1), 55-73.

(2011): "The Hicks-Moorsteen Productivity Index Satisfies the Determinateness Axiom," Manchester School, 79(4), 765-775. 
Carrington, R., C. O’Donnell, and D. RaO (2018): "Australian University Productivity Growth and Public Funding Revisited," Studies in Higher Education, p. forthcoming.

Caves, D., L. Christensen, and W. Diewert (1982): "The Economic Theory of Index Numbers and the Measurement of Inputs, Outputs and Productivity," Econometrica, 50(6), 1393-1414.

Chambers, R. (2002): "Exact Nonradial Input, Output, and Productivity Measurement," Economic Theory, 20(4), 751-765.

Chancellor, W., and M. Aвbott (2015): "Apprenticeship Training and Productivity Growth: A Case Study of the Australian Construction Industry," Australian Bulletin of Labour, 41(1), $1-15$.

Cracolici, M., P. Nijkamp, and P. Rietveld (2008): "Assessment of Tourism Competitiveness by Analysing Destination Efficiency," Tourism Economics, 14(2), 325-342.

Deller, S., And C. Nelson (1991): "Measuring the Economic Efficiency of Producing Rural Road Services," American Journal of Agricultural Economics, 72(1), 194-201.

Dwyer, L., And C. Kim (2003): "Destination Competitiveness: Determinants and Indicators," Current Issues in Tourism, 6(5), 369-414.

Epure, M., K. Kerstens, and D. Prior (2011): "Technology-Based Total Factor Productivity and Benchmarking: New Proposals and an Application," Omega, 39(6), 608-619.

Färe, R., S. Grosskopf, B. Lindgren, and P. Roos (1995): "Productivity Developments in Swedish Hospitals: A Malmquist Output Index Approach," in Data Envelopment Analysis: Theory, Methodology and Applications, ed. by A. Charnes, W. Cooper, A. Lewin, and L. Seiford, pp. 253-272. Kluwer, Boston.

Färe, R., S. Grosskopf, and J. Walden (2015): "Productivity Change and Fleet Restructuring after Transition to Individual Transferable Quota Management," Marine Policy, 62, 318-325.

Färe, R., And D. Primont (1995): Multi-Output Production and Duality: Theory and Applications. Kluwer, Boston.

Giménez-García, V., J. Martínez-Parra, and F. Buffa (2007): "Improving Resource Utilization in Multi-Unit Networked Organizations: The Case of a Spanish Restaurant Chain," Tourism Management, 28(1), 262-270.

Goncalves, O. (2013): "Efficiency and Productivity of French Ski Resorts," Tourism Management, 36, 650-657.

Hackman, S. (2008): Production Economics: Integrating the Microeconomic and Engineering Perspectives. Springer, Berlin. 
Hayes, K., and S. Chang (1990): "The Relative Efficiency of City Manager and Mayor-council Forms of Government," Southern Economic Journal, 57(1), 167-177.

Hulten, C. (2001): "Total Factor Productivity: A Short Biography," in New Developments in Productivity Analysis, ed. by C. Hulten, E. Dean, and M. Harper, pp. 1-47. University of Chicago Press, Chicago.

Islam, N., V. Xayavong, and R. Kingwell (2014): "Broadacre Farm Productivity and Profitability in South-Western Australia," Australian Journal of Agricultural and Resource Economics, $58(2), 147-170$.

Karkazis, J., And E. Thanassoulis (1998): "Assessing the Effectiveness of Regional Development Policies in Northern Greece Using Data Envelopment Analysis," Socio-Economic Planning Sciences, 32(2), 123-137.

Keh, H., And J. Chu, S.And Xu (2006): "Efficiency, Effectiveness and Productivity of Marketing in Services," European Journal of Operational Research, 170(1), 265-276.

Kerstens, K., and I. Van de Woestyne (2014): "Comparing Malmquist and Hicks-Moorsteen Productivity Indices: Exploring the Impact of Unbalanced vs. Balanced Panel Data," European Journal of Operational Research, 233(3), 749-758.

Last, A.-K., And H. Wetzel (2010): "The Efficiency of German Public Theaters: A Stochastic Frontier Analysis Approach," Journal of Cultural Economics, 34(2), 89-110.

LI, Q. (1996): "Nonparametric Testing of Closeness between Two Unknown Distribution Functions," Econometric Reviews, 15(1), 261-274.

(1999): "Nonparametric Testing the Similarity of Two Unknown Density Functions: Local Power and Bootstrap Analysis," Journal of Nonparametric Statistics, 11(1-3), 189-213.

Mairesse, F., and P. Vanden Eeckaut (2002): "Museum Assessment and FDH Technology: Towards a Global Approach," Journal of Cultural Economics, 26(4), 261-286.

Marrocu, E., and R. PaCi (2011): "They Arrive with New Information: Tourism Flows and Production Efficiency in the European Regions," Tourism Management, 32(4), 750-758.

Mcmahon, F. (1994): "Productivity in the Hotel Industry," in Tourism: The State of the Art, ed. by A. Seaton, pp. 616-625. Wiley, New York.

Molinos-Senante, M., A. Maziotis, and R. Sala-Garrido (2017): "Assessment of the Total Factor Productivity Change in the English and Welsh Water Industry: A Färe-Primont Productivity Index Approach," Water Resources Management, 31(8), 2389-2405. 
Nemoto, J., and M. Goto (2005): "Productivity, Efficiency, Scale Economies and Technical Change: A New Decomposition Analysis of TFP Applied to the Japanese Prefectures," Journal of the Japanese and International Economies, 19(4), 617-634.

Nguyen, P., and M. Simioni (2015): "Productivity and Efficiency of Vietnamese Banking System: New Evidence using Färe-Primont Index Analysis," Applied Economics, 47(41), 4395-4407.

Nishimizu, M., And J. Page (1982): "Total Factor Productivity Growth, Technological Progress and Technical Efficiency Change: Dimensions of Productivity Change in Yugoslavia, 1965-78," Economic Journal, 92(368), 920-936.

O’Donnell, C. (2011a): "DPIN 3.0: A Program for Decomposing Productivity Indices," Centre for efficiency and productivity analysis, University of Queensland, Brisbane.

(2011b): "The Sources of Productivity Change in the Manufacturing Sectors of the U.S. Economy," Centre for Efficiency and Productivity Analysis Working Papers WP07/2011, University of Queensland, Brisbane.

- (2012): "An Aggregate Quantity-Price Framework for Measuring and Decomposing Productivity and Profitability Change," Journal of Productivity Analyis, 38(3), 255-272.

(2014): "Econometric Estimation of Distance Functions and Associated Measures of Productivity and Efficiency Change," Journal of Productivity Analyis, 41(2), 187-200.

OtgaAr, A. (2012): "Towards a Common Agenda for the Development of Industrial Tourism," Tourism Management Perspectives, 4, 86-91.

Pastor, J. T., And C. K. Lovell (2005): "A Global Malmquist Productivity Index," Economic Letters, 88(1), 266-271.

Peypoch, N., and B. Solonandrasana (2008): "Aggregate Efficiency and Productivity Analysis in the Tourism Industry," Tourism Economics, 14(1), 45-56.

Peyrache, A. (2014): "Hicks-Moorsteen versus Malmquist: A Connection by Means of a Radial Productivity Index," Journal of Productivity Analysis, 41(3), 435-442.

Puig-Junoy, J. (2001): "Technical Inefficiency and Public Capital in U.S. States: A Stochastic Frontier Approach," Journal of Regional Science, 41(1), 75-96.

Pulina, M., C. Detotto, and A. Paba (2010): "An Investigation into the Relationship between Size and Efficiency of the Italian Hospitality Sector: A Window DEA Approach," European Journal of Operational Research, 204(3), 613-620.

Rahman, S., and R. Salim (2013): "Six Decades of Total Factor Productivity Change and Sources of Growth in Bangladesh Agriculture (1948-2008)," Journal of Agricultural Economics, 64(2), 275-294. 
Ramos, X., and J. Silber (2005): "On the Application of Efficiency Analysis to the Study of the Dimensions of Human Development," Review of Income and Wealth, 51(2), 285-309.

Ritchie, J., and G. Crouch (2003): The Competitive Destination: A Sustainable Tourism Perspective. CABI, Wallingford.

Seifert, S., And M. Nieswand (2014): "What Drives Intermediate Local Governments' Spending Efficiency: The Case of French Départements," Local Government Studies, 40(5), 766-790.

Sellers-Rubio, R., and J. Nicolau-GonzÁlbez (2009): "Assessing Performance in Services: The Travel Agency Industry," Service Industries Journal, 29(5), 653-667.

Somarriba, N., And B. Pena (2009): "Synthetic Indicators of Quality of Life in Europe," Social Indicators Research, 94(1), 115-133.

Widodo, W., R. Salim, and H. Bloch (2014): "Agglomeration Economies and Productivity Growth in Manufacturing Industry: Empirical Evidence from Indonesia," Economic Record, 90(s1), 41-58.

Wober, K., And D. Fesenmaier (2004): "A Multi-Criteria Approach to Destination Benchmarking: A Case Study of State Tourism Advertising Programs in the United States," Journal of Travel \& Tourism Marketing, 16(2-3), 1-18.

Yu, M.-M., And L.-H. Chen (2016): "Productivity Growth of Taiwanese International Tourist Hotels in a Metafrontier Framework," Cornell Hospitality Quarterly, 57(1), 38-50.

Zaim, O., R. Färe, and S. Grosskopf (2001): "An Economic Approach to Achievement and Improvement Indexes," Social Indicators Research, 56(1), 91-118. 


\section{Appendix: Computing Distance Functions (Supplementary Mater- ial)}

The computation of the F-P productivity index (3) for any two observations $k$ and $l$ requires calculating four efficiency values. The linear programming problems are defined relative to a variable returns to scale technology which is also assumed in the empirical results reported in this contribution.

The F-P input quantity index consists of two input efficiency values that can be obtained from solving the following LP for $p=l$ and $p=k$, respectively:

$$
\begin{aligned}
& {\left[D_{i}\left(x^{p}, y^{o}\right)\right]^{-1}=\min _{\theta, z_{j}} \theta} \\
& \text { subject to } \sum_{j=1}^{K} z_{j} y_{j m} \geq y_{m}^{o} \quad m=1, \ldots, M, \\
& \sum_{j=1}^{K} z_{j} x_{j n} \leq \theta x_{j n}^{p} \quad n=1, \ldots, N \\
& \sum_{j=1}^{K} z_{j}=1 \\
& z_{j} \geq 0, \quad j=1, \ldots, K .
\end{aligned}
$$

The F-P output quantity index contains two output efficiency values derived from solving the following LP for $p=l$ and $p=k$, respectively:

$$
\begin{aligned}
{\left[D_{o}\left(x^{o}, y^{p}\right)\right]^{-1}=} & \max _{\theta, z_{j}} \theta \\
\text { subject to } & \sum_{j=1}^{K} z_{j} y_{j m} \geq \theta y_{j m}^{p} \quad m=1, \ldots, M, \\
& \sum_{j=1}^{K} z_{j} x_{j n} \leq x_{n}^{o} \quad n=1, \ldots, N, \\
& \sum_{j=1}^{K} z_{j}=1, \quad j=1, \ldots, K .
\end{aligned}
$$

The sub-vector F-P productivity index (7) for any two observations $k$ and $l$ needs four modified efficiency values. Again, we present the corresponding linear programming problems relative to a variable returns to scale technology. 
The sub-vector F-P input quantity index consists of two modified input efficiency values that can be obtained from solving the following $\operatorname{LP}$ for $p=l$ and $p=k$, respectively:

$$
\begin{aligned}
& {\left[D_{i}\left(x_{v}^{p}, x_{f}^{p}, y^{o}\right)\right]^{-1}=\min _{\theta, z_{j}} \theta} \\
& \text { subject to } \sum_{j=1}^{K} z_{j} y_{j m} \geq y_{m}^{o} \quad m=1, \ldots, M, \\
& \sum_{j=1}^{K} z_{j} x_{j n} \leq \theta x_{j n}^{p} \quad n \in\{\text { variable input dimensions }\}, \\
& \sum_{j=1}^{K} z_{j} x_{j n} \leq x_{j n}^{p} \quad n \in\{\text { fixed input dimensions }\}, \\
& \sum_{j=1}^{K} z_{j}=1 \\
& z_{j} \geq 0, \quad j=1, \ldots, K \text {. }
\end{aligned}
$$

Finally, the sub-vector F-P output quantity index contains two modified output efficiency values derived from solving the following LP for $p=l$ and $p=k$, respectively:

$$
\begin{aligned}
& {\left[D_{o}\left(x^{o}, y_{v}^{p}, y_{f}^{p}\right)\right]^{-1}=\max _{\theta, z_{j}} \theta} \\
& \text { subject to } \sum_{j=1}^{K} z_{j} y_{j m} \geq \theta y_{j m}^{p} \quad m \in\{\text { variable output dimensions }\} \text {, } \\
& \sum_{j=1}^{K} z_{j} y_{j m} \geq y_{j m}^{p} \quad m \in\{\text { fixed output dimensions }\} \\
& \sum_{j=1}^{K} z_{j} x_{j n} \leq x_{n}^{o} \quad n=1, \ldots, N \\
& \sum_{j=1}^{K} z_{j}=1 \\
& z_{j} \geq 0, \quad j=1, \ldots, K \text {. }
\end{aligned}
$$

